\title{
History of Civilizations of Central Asia. Volume VI : Towards the contemporary period: from the mid- nineteenth to the end of the twentieth century. Paris, UNESCO Publishing, 2005, 1033 p.
}

\section{Alexandre Papas}

\section{(2) OpenEdition}

\section{Journals}

Édition électronique

URL : http://journals.openedition.org/abstractairanica/16962

DOI : 10.4000/abstractairanica.16962

ISSN : 1961-960X

Éditeur :

CNRS (UMR 7528 Mondes iraniens et indiens), Éditions de l'IFRI

Édition imprimée

Date de publication : 15 mai 2007

ISSN : 0240-8910

\section{Référence électronique}

Alexandre Papas, « History of Civilizations of Central Asia. Volume VI : Towards the contemporary period: from the mid-nineteenth to the end of the twentieth century. Paris, UNESCO Publishing, 2005, 1033 p. », Abstracta Iranica [En ligne], Volume 28 | 2007, document 141, mis en ligne le 18 septembre 2007, consulté le 25 septembre 2020. URL : http://journals.openedition.org/abstractairanica/16962 ; DOI : https://doi.org/10.4000/abstractairanica.16962

Ce document a été généré automatiquement le 25 septembre 2020.

Tous droits réservés 


\title{
History of Civilizations of Central Asia. Volume VI : Towards the contemporary period: from the mid- nineteenth to the end of the twentieth century. Paris, UNESCO Publishing, 2005, $1033 \mathrm{p}$.
}

\author{
Alexandre Papas
}

Ultime volume d'une série qui se veut couvrir l'entière histoire de l'Asie centrale, de l'Antiquité à nos jours, cet épais ouvrage possède les qualités et les défauts du genre. Ainsi il n'est pas certain que des chapitres consacrés à l'Iran, au Pakistan et à l'Inde (ch. $4,8,17,18,20,22 / 3,27 / 2$ ) soient pertinents. Davantage l'auraient été des développements sur le Xinjiang qui n'est traité (superficiellement) que dans les chapitres 16 et 26/1-2. D'autre part, la littérature, qui fait l'objet des chapitres 30 et 31, n'est sérieusement étudiée que par G. Kara pour les lettres mongoles. Plus généralement, l'histoire intellectuelle (à l'exception, il est vrai, du ch. 7) et l'histoire religieuse sont peu abordées. Nonobstant ces travers, on gagnera à lire les synthèses historiques proposées par V. Fourniau, C. Poujol et A. Tabyshalieva (ch. 1, 2 et 3). Tandis que le ch.5 (N.A.Abdurakhimova) consacré à la période coloniale russe, éclaire notamment la question des waqf sous administration tsariste, le ch. 6 détaille les événements de la révolution bolchevique en Asie centrale, à l'aide de sources diverses dont les fonds d'archives des républiques. Caractérisé chacun par une historiographie classique sans doute utile (mais par une trop classique indifférence à la littérature secondaire occidentale), les chapitres 9, 10,11, 12 et 13 traitent des cinq républiques de la période soviétique aux indépendances, tandis que les chapitres 14 et 15/1-2-3 portent sur les régions septentrionales et plus longuement sur la Mongolie et la création de la République populaire mongole en 1924-26. Suivent des recherches thématiques: dans la vogue des gender studies, l'analyse du statut de la femme en Asie 
centrale soviétique et dans l'Afghanistan du XXe s. (ch. 22/1-2, par D. A. Alimova et A. Kian-Thiébaut) représente un cas d'étude qui reste à développer dans le sens d'une anthropologie historique. Les arts ne sont bien sûr pas oubliés et sont peut-être les chapitres les plus intéressants et, naturellement, les mieux illustrés de ce volume : ainsi l'artisanat et la peinture moderne des républiques centre-asiatiques sont présentés en détail par A. Khakimov au ch. 25 ; les arts et l'architecture de Mongolie extérieure (en particulier religieux) sont savamment décrits par Ch. Atwood au ch. 26/3; L. Adams retrace l'histoire du cinéma et du théâtre de l'Asie centrale soviétique et postsoviétique dans le ch. 28 ; enfin, le ch. 29, signé M. Azzout, sur l'architecture et l'organisation urbaine de l'Ouzbékistan (entre 1865 et 1990) constitue une étude bien documentée et originale. Au total, il s'agit d'un ouvrage de collation qui n'ambitionne pas la nouveauté pour rester fidèle à son projet, à savoir celui de soumettre une histoire générale et accessible au lecteur non-spécialiste.

INDEX

Thèmes : 4.0. Généralités

\section{AUTEURS}

ALEXANDRE PAPAS

EHESS - Paris 